\title{
DESIGN AND IMPLEMENTATION OF MICROCONTROLLER BASED PHOTOACOUSTIC SPECTROMETER AND ITS APPLICATIONS
}

\author{
Sapna Shukla, J Immanuel and P.Bhaskar \\ Department of Instrumentation Technology, Gulbarga University, Post-Graduation Centre, \\ Yeragera, RAICHUR-584101, Karnataka, India
}

\begin{abstract}
:
A compact microcontroller based photoacoustic spectrometer (PAS) has been designed and fabricated. The photoacoustic (PA) cell designed for the present study is of Helmholtz resonator type with a provision to measure the sample behavior as a function of temperature. In this system, an electret microphone is employed to achieve high signal to noise ratio. The microphone compartment is isolated from the sample compartment to avoid the heating effect to the electric microphone which detects the photoacoustic signal. A high-gain low-noise two stage preamplifier, second order bandpass and tunable narrow band-pass filters have been designed with a low noise op-amp LM308 to improve signal quality. C8051F060 microcontroller-based phase sensitive detector has been implemented to measure the amplitude and phase of the signal from the photoacoustic cell. The applications of PAS for phase transition studies on some samples are presented. The designed system is low-cost, very compact and easy to carry the experiments for studying the thermal properties of samples.
\end{abstract}

Keywords: PAS, photoacoustic spectrometer, phase sensitive detector

Cite this Article: Sapna Shukla, J Immanuel and P.Bhaskar, Design and Implementation of Microcontroller Based Photoacoustic Spectrometer and its Applications, International Journal of Advanced Research in Engineering and Technology, 10(1), 2019, pp 1-10.

http://iaeme.com/Home/issue/IJARET?Volume=10\&Issue $=1$

\section{INTRODUCTION}

Photoacoustic spectroscopy is becoming a popular technique for examining different samples, due to the advantages such as the technique is faster, requires less sample preparation and yields more reproducible results. The wealth information contained in the PA signal can be used to investigate the variations in the optical and thermal properties of materials during phase transitions. In general, several reports have been available on the use of PA technique for the investigation of phase transitions in solids [1-10]. Few authors reported the application of PA effect to study the phase transitions and thermal properties of liquids crystals [11-12]. The origin of photoacoustic spectroscopy dates back to the discovery of the photoacoustic effect by

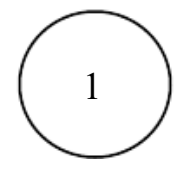


Alexander Graham Bell in 1880 [13]. He found that thin discs emit sound when exposed to a rapidly interrupted beam of sunlight [14]. By placing different absorbing substances in contact with the ear using a hearing tube, he was able to detect absorption in both the visible and the invisible regions of the solar spectrum. This spectrophone was used in his experiments on wireless transmission of sound. The practical use of the photoacoustic effect for condensed phase materials had to wait for advances in instrumentation and theory. In 1973, PAS was rediscovered by A. Rosencwaig and Gersho at Bell Laboratories. A general theory for the photoacoustic effect was developed by Rosencwaig and Gersho [15] and is commonly referred to as the RG Model.

In order to carry out the phase transition studies through the photoacoustic technique, we have designed and developed a microcontroller-based instrumentation system indigenously and employed it for phase transition studies of some compounds.

\section{PRINCIPLE}

Photoacoustic (PA) effect is basically generation of acoustic waves on irradiating certain substances by a modulated radiation source. Thus, when the sample is irradiated by modulated electromagnetic wave, absorption of photons (photo energy) generates excited internal energy levels. All or part of the absorbed photon energy is then transformed into heat (thermal energy) through non-radiative relaxation processes in the sample. Since the radiation incident on the sample is intensity modulated, the internal heating of the sample is also modulated at the same frequency. The air at the sample and gas interface undergoes compression and rarefactions by this internal heating of the sample, which in turn produces acoustic signal of same frequency as that of the modulating signal. This acoustic signal is converted into electrical signal by the microphone. This signal is filtered and measured by the microcontroller-based system. The Fig. 1 shows the block diagram of microcontroller based photoacoustic spectrometer. It consists of $50 \mathrm{~mW}(808 \mathrm{~nm})$ IR laser source, PA cell, microphone, pre-amplifier, band-pass filter, narrow-band-pass filter and microcontroller with LCD module.

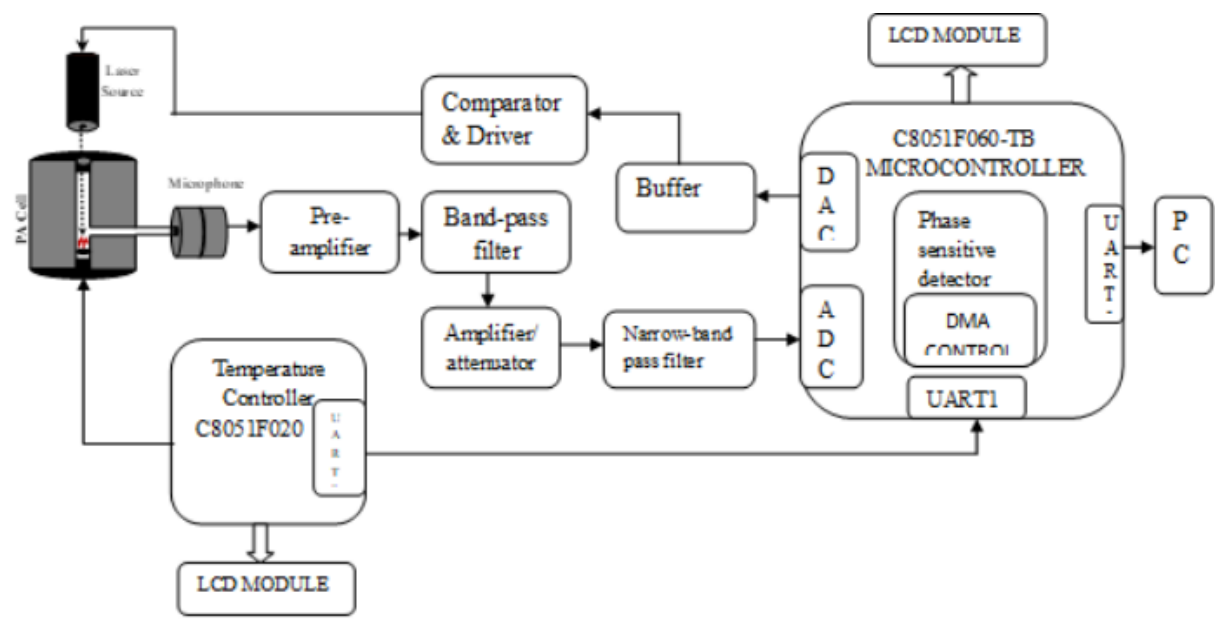

Fig 1 Block Diagram of Microcon troller based Photo acoustic Sp ectrometer

\section{PHOTOACOUSTIC CELL}

The PA cell design can be considered as the heart of the PAS and ultimate aim in cell design is maximizing the signal to noise ratio. The PA cell used in the present study is designed according to the Helmholtz resonance principle [12]. It has been constructed with a view to achieve high sensitivity and to expand the operating ranges for the temperature up to $500^{\circ} \mathrm{C}$ and frequency up to $1 \mathrm{kHz}$ specifically for the study of phase transitions in solids. The cell is made from copper cylindrical block of dimension $3.0 \mathrm{~cm}$ length, $3.0 \mathrm{~cm}$ diameter and $1.0 \mathrm{~cm}$ inner diameter and it 
is coated with chromium. A cylindered tube of $0.5 \mathrm{~mm}$ inner diameter and $4.0 \mathrm{~cm}$ length is welded near sample cavity, which acts as resonating column of the cell. The microphone chamber $(2.5 \mathrm{~cm}$ length, $3.0 \mathrm{~cm}$ diameter and $1.0 \mathrm{~cm}$ inner diameter for placing microphone $)$ is welded on top of the tube, which acts as acoustic signal detector. There is a glass window for laser source to enter and fall on sample cavity. The glass windows are fitted air tight with silica O-ring and align screws. Similarly, a silica O-ring is employed in the microphone chamber to arrest air leakages.

\section{RADIATION SOURCE}

Incandescent lamps or arc lamps are normally used as radiation sources for PA studies. But lasers have found wide acceptance as convenient radiation sources in PA studies owing to their highly collimated beam of extremely high spectral brilliance, relatively high power and the narrow-band emission in visible and near infrared regions, and the advantage that it can be easily modulated by just modulating the voltage applied to the diode. Further, the fact that they are compact, inexpensive and easy to handle make it an ideal choice for uses in small, sample specific PA cell. A switchable diode laser with a power of $50 \mathrm{~mW}$ and wavelength of $808 \mathrm{~nm}$ has been used for the present study. The laser beam is modulated by connecting diode laser in the collector of a transistor and modulating signal (TTL square wave) applied to the base of the transistor.

\section{ACOUSTIC SIGNAL DETECTOR}

In the present work an electret microphone has been employed. It works on the same principle as the condenser, but with the difference that the capacitance is provided by the electret, which is a thin foil of material with a permanent electrical polarization and high dielectric constant. One side of the electret foil is metalized and the insulating side is placed on fixed back plate. The impinging sound waves on the metalized foil cause a change in polarization characteristics of the electret material which in turn provide small voltage between the metalized front electret and the fixed back plate. KECG3644PFJ - an electret microphone of KSA [16] Electronics make is employed for the present study.

\section{PRE-AMPLIFIER}

The high-gain low-noise pre-amplifier [17] is designed with two stages to improve the gainband-width product of the amplifier. The op-amps A1 and A2 constitutes two-stage preamplifier as shown in Fig. 3. It has gain of 10 in first stage and 100 in second stage with a total gain of 1000. The gain of the pre- amplifier can be varied by varying the potentiometer connected in the feedback of the op-amp A2. The signal obtained from the pre-amplifier is normally associated with some unwanted frequency components, but to get output at one particular frequency these unwanted frequencies are to be eliminated. This band of unwanted frequencies is eliminated by the tunable narrow band-pass filter which improves the signal-tonoise ratio of the circuit

\section{BAND-PASS FILTER}

The Fig. 3 shows the band-pass filter designed for the present application. . The op-amps A3 and A4 constitutes band-pass filter. The signal to noise ratio is the most important parameter that needs to be considered in the PAS, hence the use of noise filter becomes a necessity when low level measurements or high-resolution measurements are attempted. The second order band-pass filter is designed by using LM308 op-amp. The narrow-band-pass filter is designed by cascading the second order high-pass and second order low-pass filter. The cut-off frequency 
for high-pass and low-pass filter is designed for $352 \mathrm{~Hz}$. The values of resistors and capacitors of the filter are calculated as given below:

$$
\begin{aligned}
& \text { For } \mathrm{f}_{\mathrm{c}}=352 \mathrm{~Hz} \text {, assume } \mathrm{C}_{1}=\mathrm{C}_{2}=\mathrm{C}=0.1 \mu \mathrm{F} \\
& f_{c}=\frac{1}{2 \pi R C} \\
& \mathrm{R}_{1}=\mathrm{R}_{2}=\mathrm{R} ; \\
& R=\frac{1}{2 X 3.142 \times 0.1 \times 10^{-6} \times 352}=4.52 k \cong 4.7 k
\end{aligned}
$$

\section{NARROW BAND-PASS FILTER}

The output of band-pass filter is given to the narrow band-pass for further improvement in $\mathrm{S} / \mathrm{N}$ ratio. The op-amp A7 A8, A9 and A10 constitutes narrow band-pass filter. The Fig.3 shows the state-variable tunable band-pass filter for the present system. The narrow band-pass filter, in spite of large number of components, is a good choice for very sharp (high-Q) band-pass filters. It has low component sensitivities, do not make great demands on operational amplifiers bandwidth and it is easy to tune such filters. The important advantage of narrow band-pass filter is that, its bandwidth (i.e., Q) can be adjusted without affecting the mid-band gain. In fact, both $\mathrm{Q}$ and gain are set with a single resistor each $\left(\mathrm{R}_{\mathrm{Q}}\right.$ and $\left.\mathrm{R}_{\mathrm{G}}\right)$. $\mathrm{Q}$, gain and center frequency are completely independent and are given by the following simple equations

$$
\begin{aligned}
& \mathrm{f}_{\mathrm{o}}=1 /\left(2 \Pi \mathrm{R}_{\mathrm{F}} \mathrm{C}\right) \\
& \mathrm{Q}=\mathrm{R}_{1} / \mathrm{R}_{\mathrm{Q}} \\
& \mathrm{G}=\mathrm{R}_{1} / \mathrm{R}_{\mathrm{G}}
\end{aligned}
$$

The present circuit is designed for $\mathrm{Q}=50$ and $\mathrm{G}=10$. In this circuit a ganged potentiometer is used as feed-back resistor $\left(\mathrm{R}_{\mathrm{F}}\right)$. By varying the ganged potentiometer center frequency can be adjusted to the desired value. With this arrangement, the frequency range from $10 \mathrm{~Hz}$ to $600 \mathrm{~Hz}$ can be covered which is well beyond the range required for the present study.

\section{TEMPERATURE CONTROL SYSTEM}

The microcontroller-based temperature control system is designed and the temperature of the photoacoustic cell is measured by using Pt-100 temperature sensor. Pt-100 produces change in resistance with change in temperature. This change in resistance is converted into change in voltage by using constant current source. The voltage corresponds to temperature is converted into digital data by the on-chip ADC of C8051F020 microcontroller. The digital data is converted into actual temperature by substituting it in the equation

$$
\text { Temperature }=(2.657 * \text { voltage })-273.0
$$

The equation [6] is derived from the temperature v/s output voltage graph of Pt-100 (y = $\mathrm{mx}+\mathrm{C}$ ). The present temperature of the photoacoustic cell is displayed on the LCD module. The microcontroller compares the actual temperature with the set value and error is calculated. Then error is applied to the PID control algorithm. The control algorithm is implemented by writing embedded ' $\mathrm{C}$ ' program. The output of the algorithm is fed into on-chip timer- 0 . The output from P6.0 of the microcontroller is connected to the opto-isolator (MOC 3010) which controls the firing angle of the triac. The firing angle is decided by the count in the timer- 0 of the microcontroller which is proportional to the solution of PID equation. 
The usual method of controlling an alternating voltage (ac mains) is to vary the firing angle of triac. The small count in the timer- 0 takes large time to overflow, this produces small conduction angle (and hence small ON-time) and a small output power to the load conversely a large count in the timer- 0 will take less time for counter to overflow causing a large conduction angle (large ON time). Hence, larger power is applied to the load. This variation in duty cycle controls the firing angle of the triac and hence an amount of energy supplied to the heater. Thus, the later maintains the temperature of the photoacoustic cell at the desired value. The PID temperature controller designed is found to regulate the temperature of the photoacoustic cell with in $\pm 0.1^{\circ} \mathrm{C}$.

\section{MICROCONTROLLER BASED PHASE SENSITIVE DETECTOR}

The output of the narrow band-pass filter is given to microcontroller-based phase sensitive detector. The phase sensitive detector is implemented through C8051F060 microcontroller. C8051F060 microcontroller has been employed in the present system. This microcontroller is good example for system-on-chip. It contains all the features to design a single chip instrument [18].

As the name implies PSD is sensitive to the phase difference between two input ac signals that are at the same frequency. The PSD is used to improve the signal-to-noise ratio in ac signal measurements, The ADC0 can be initiated from various sources such as AD0BUSY bit, Timer2 overflow, Timer3 overflow, and external trigger.

The block diagram of microcontroller-based phase sensitive detector is as shown in the Fig.2 it is important that all the clocks for sampling, and signal generation need to be synchronized because of a possible change in phase relationship of the signal with the change in timings. For this reason, the system clock has been used for working of all peripherals. The ADC0 conversion is derived from Timer3 overflow and it is set to produce the start-ofconversion signal for every $710.2 \mu \mathrm{Sec}$ (T/4 of the signal generated by DAC). DAC will generate $352 \mathrm{~Hz}$ signal with a sampling frequency of $100 \mathrm{kHz}$ which acts as a reference signal. This sine wave is converted into square wave and is used for switching the laser diode which in turn generates acoustic signal. The signal is acquired through on-chip ADC with 16-bit resolution. The ADC acquires with $\mathrm{T} / 4$ of DAC sampling frequency, this gives 4 data samples for each cycle of $352 \mathrm{~Hz}$ signal. the sampled data is stored directly on data RAM through DMA controller. 64KB of data-RAM is available on C8051F060TB board. Hence, about 1600 cycles can be sampled and stored. In the present system 800 cycles (4 data samples for each cycle of $352 \mathrm{~Hz}$ signal) at the sampling rate of $1408 \mathrm{~Hz}$ will be stored. After collecting the quadrature samples, they will be processed to find amplitude and phase of the signal and are displayed on LCD. The X' and Y' of 800 waves are averaged to eliminate random noise of the signal and to get $\mathrm{X}$ and $\mathrm{Y}$. These $\mathrm{X}$ and $\mathrm{Y}$ values are used to calculate amplitude and phase by using the following relations.

$$
\begin{gathered}
\text { Amplitude }=\sqrt{ }\left(\mathrm{X}^{2}+\mathrm{Y}^{2}\right) \\
\text { Phase }=\tan ^{-1}(\mathrm{Y} / \mathrm{X})
\end{gathered}
$$


Sapna Shukla, J Immanuel and P.Bhaskar

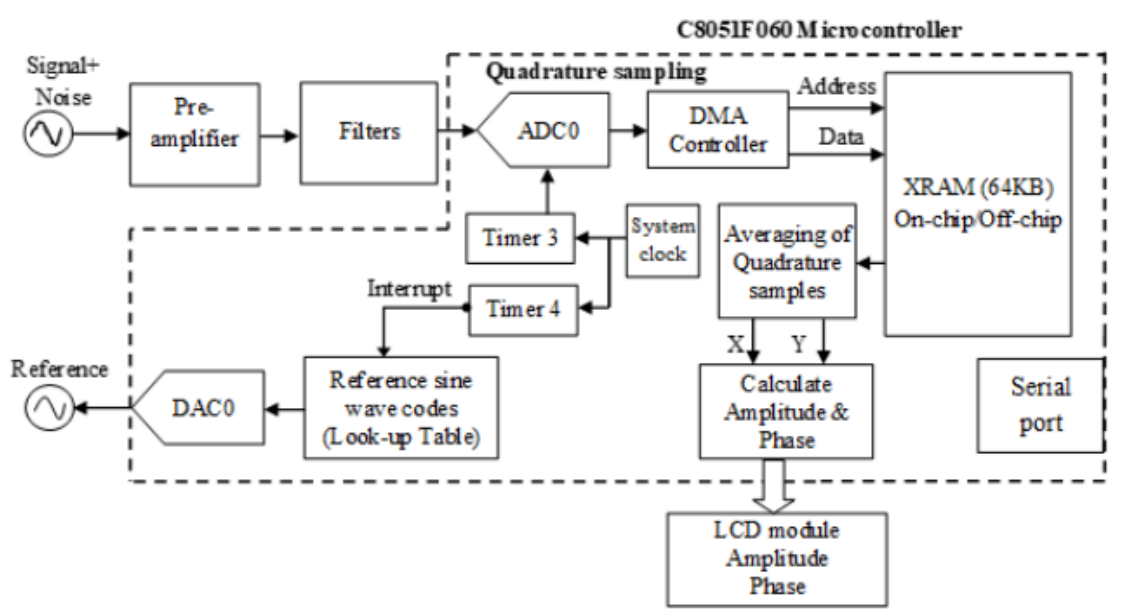

Fig.2. Microcontroller based phase sen sitive detector

\section{WORKING OF THE PHOTOACOUSTIC SPECTROMETER}

The complete circuit schematic of the PAS system is shown in Fig.3. As discussed earlier it consists of $50 \mathrm{~mW}$ IR laser $(808 \mathrm{~nm})$ source, photoacoustic (PA) cell, microphone, microcontroller-based phase sensitive detector. The sample under investigation can be either in pellet form or be directly placed in the sample cavity of the PA cell. The sample is irradiated by modulated laser beam, as a result, the absorption of light energy by the sample generates acoustic signal of same frequency as that of the laser modulating signal.

The acoustic signal generated from the PA cell is converted into electrical signal by a microphone. This signal is amplified by a high input impedance, high gain, and low noise amplifier designed using LM308 operational amplifier. The signal to noise ratio is further improved by passing through a band-pass and a narrow-band pass filter. The filter output is given to on-chip ADC0 of C8051F060 microcontroller. The on-chip A/D converter is unipolar, hence the signal applied to this A/D converter should be unipolar. The C8051F060TB board contains signal shifting circuits which shifts DC level of the signal to convert into unipolar signal. ADC0 acquires this signal every $710.2 \mu \mathrm{sec}$ (T/4 of the signal generated by DAC) The sampled data will be stored directly on data RAM through on-chip DMA controller. Since $64 \mathrm{~KB}$ of data-RAM is available on C8051F060TB board, hence about 800 cycles (4 data samples for each cycle of $352 \mathrm{~Hz}$ signal) at the sampling frequency of $1408 \mathrm{kHz}$ will be stored. After collecting these samples, the results of any subsequent data points are ignored until the current data has been processed. The digital data acquired is then averaged to eliminate random noise and processed for finding the amplitude and phase of the signal and displayed the same on the LCD module.

A temperature controller is employed to study the sample behaviour as a function of temperature [19] A C8051F020 based PID temperature control system will vary the temperature of the PA cell from room temperature to $300^{\circ} \mathrm{C}$ at desired rate (for present study it is $1{ }^{\circ} \mathrm{C} / \mathrm{Min}$ ). The amplitude and phase of the photoacoustic signal are recorded as a function of temperature. The amplitude, phase, and temperature data are communicated and stored in the PC through the on-chip serial port (UART0) for further analysis of the data. Fig.4 shows the Photograph of the complete system. 
Design and Implementation of Microcontroller based Photoacoustic Spectrometer and its Applications
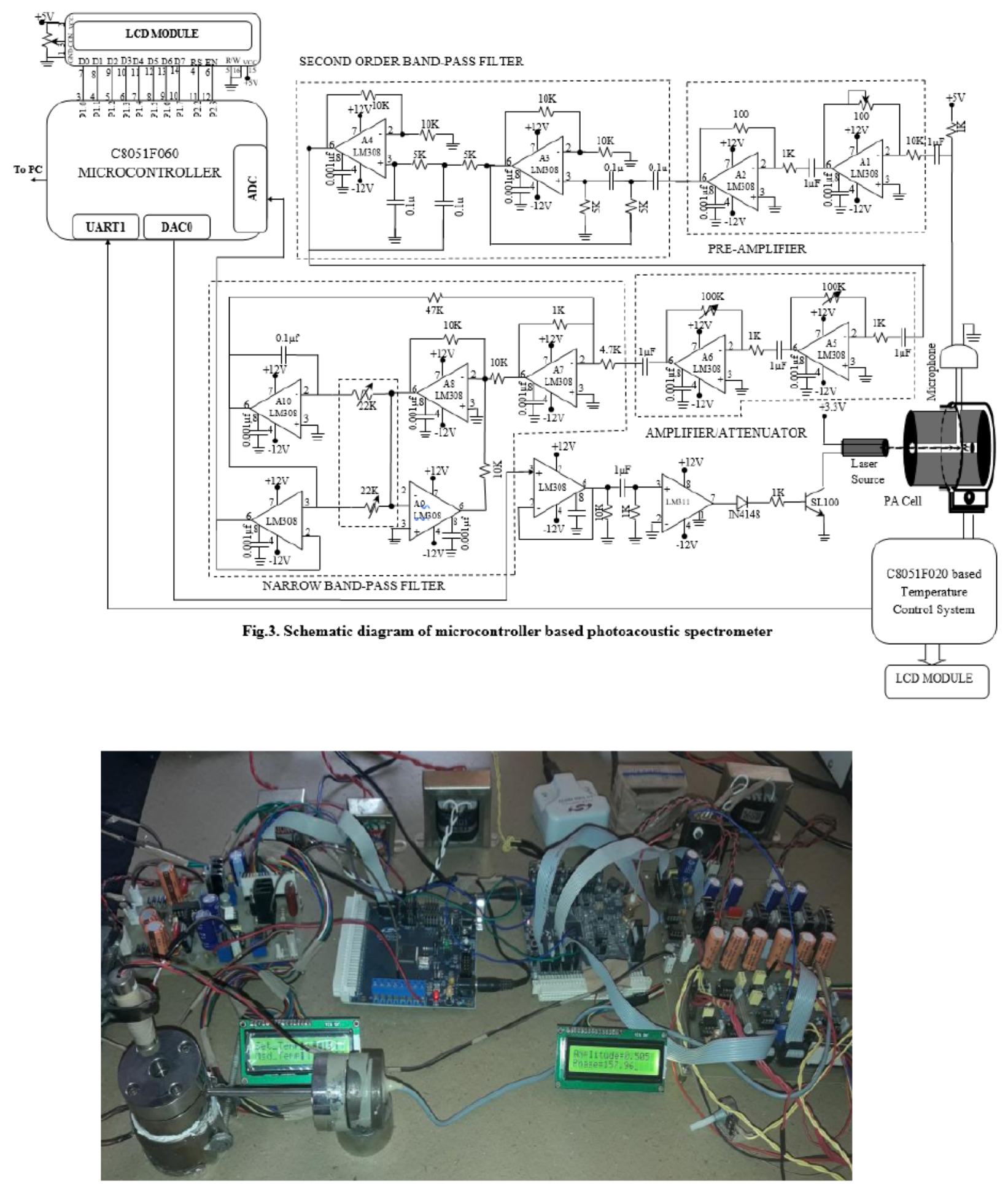

Figure 4 Photograph of the complete system.

\section{RESULTS AND CONCLUSIONS}

The phase transition of some compounds such as Urea, Cinnamic acid, Benzoic acid Acetaldehyde and Sulphor have been studied. The graphs show the variation in amplitude of the PA signal with temperature respectively. It is observed that there are sudden changes in the PA signal amplitude at particular temperatures which is solid-liquid transition temperature of 
the particular sample. The DSC graphs for the same compounds are also presented, PAS graphs are in good in agreement with the DSC. The above results obtained through the PAS studies on the standard samples, establish the reliability of the designed photoacoustic spectrometer for studying the phase transition of the samples. Hence the system can be applied to study the phase transition of samples such as liquid crystals etc.

C8051F060 microcontroller based photoacoustic spectrometer is designed and fabricated. This approach makes the instrument very compact, low cost, low power consumption, and versatile.

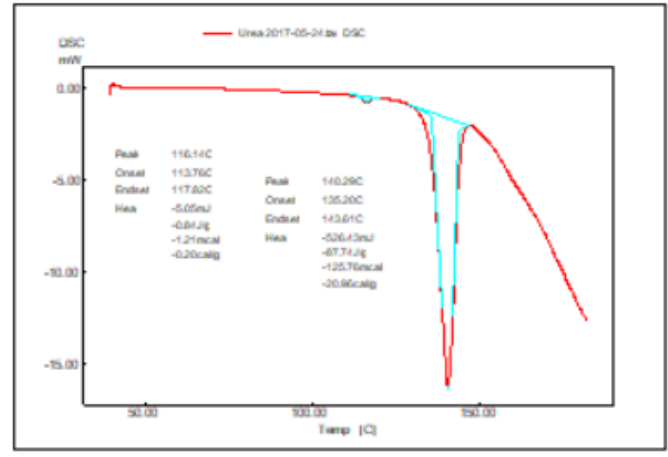

(a)

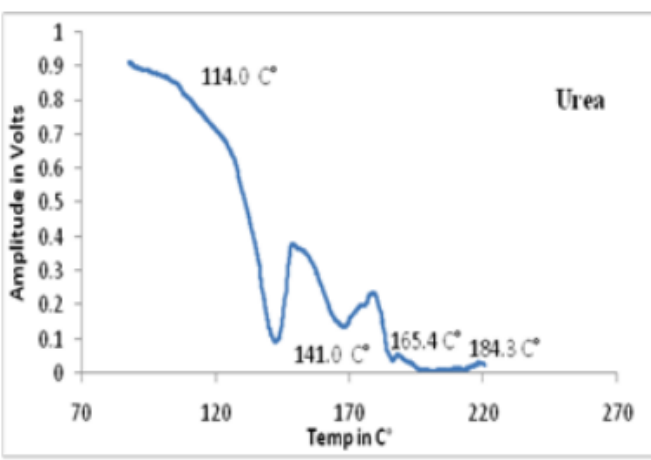

(b)

Figure 5 Phase Transitions of Urea observed in (a) DSC (b) PAS

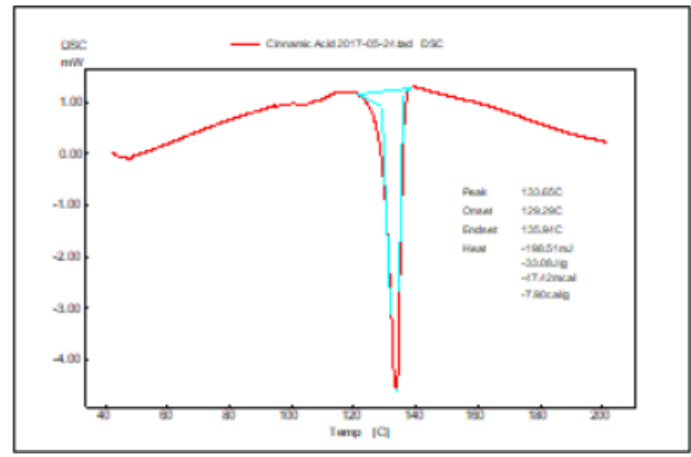

(a)

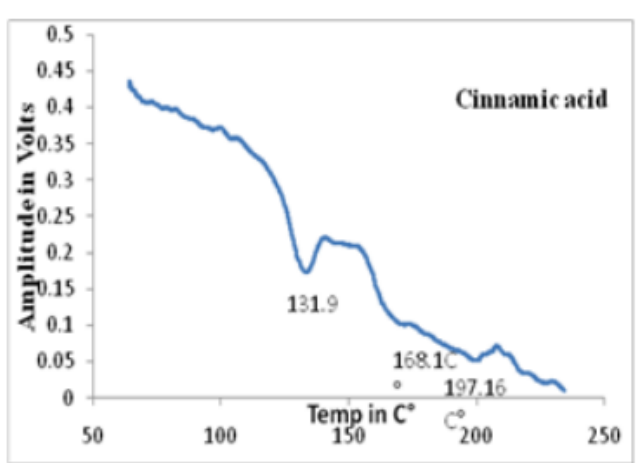

(b)

Figure 6 Phase Transitions of Cinnamic Acid observed in (a) DSC (b) PAS

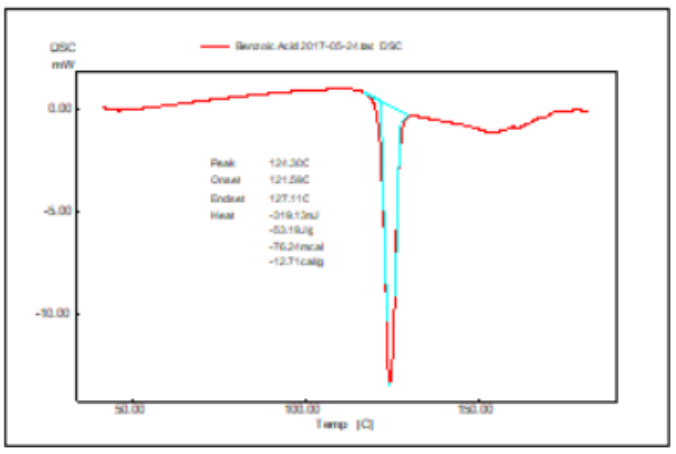

(a)

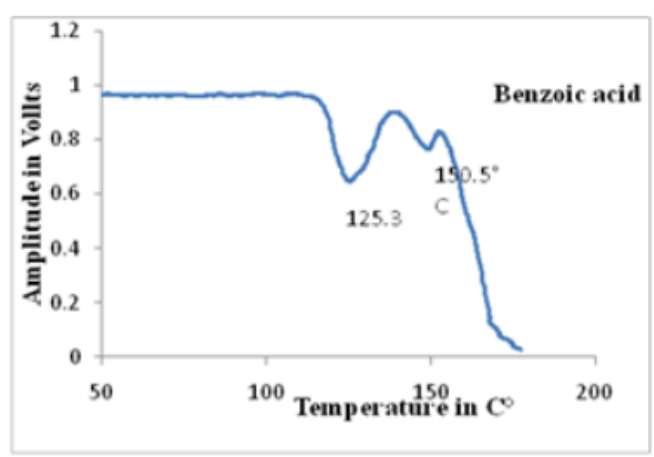

(b)

Figure 7 Phase Transitions of Benzoic Acid observed in (a) DSC (b) PAS 
Design and Implementation of Microcontroller based Photoacoustic Spectrometer and its Applications

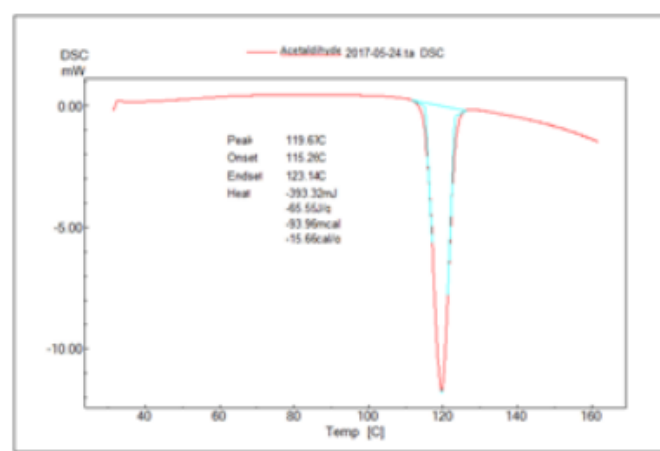

(a)

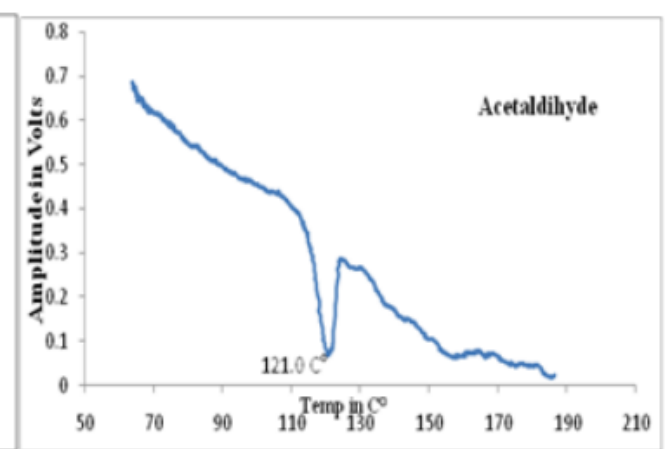

(b)

Figure 8 Phase Transitions of Acetaldihyde observed in (a) DSC (b) PAS

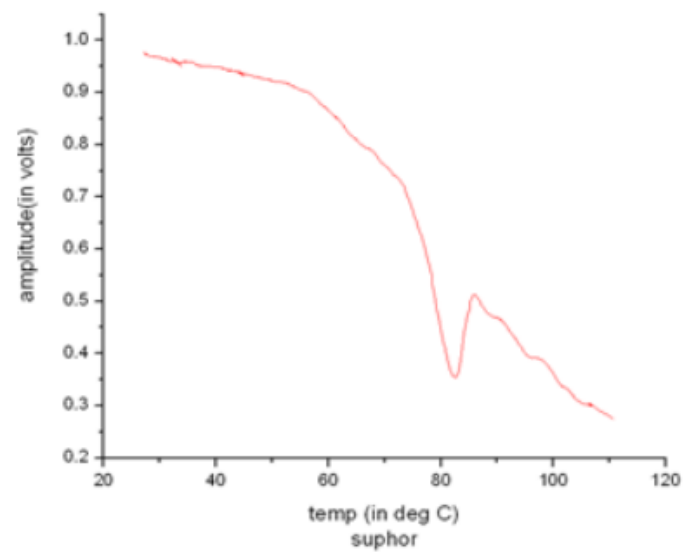

Figure 9 Phase Transitions of Sulphor observed in PAS

\section{REFERENCES}

[1] Florian, R., Pelzel, J., Rosenberg, M., Vargas, H. and Wernhardt, R., Phys. Status Solidi (a), 48, K35, 1978.

[2] Pichon, C., Leliboux, M., Fournier, D. and Boccara, A.C., Appl. Phys Lett., 35, Pp. 435, 1979.

[3] Siqueira, M. A. A., Ghizoni, C.C., Vargas, J.I., Menezes, E.A., Vargas, H and Miranda, L.C.M., J. Appl. Phys., 51, Pp.1403,1980.

[4] Bibi, I, and Jenkins, T.E., J. Phys. C. 16. L57,1987.

[5] Fernandez, J., Etxebarria, J., Tello, M.G and Lopez Echarri, A, J. Phys., D: Appl. Phys., 16, pp. $269,1983$.

[6] Etxebarria J., Uriarte, S., Fernandez, J., Tello, M.J and Gomez Cuevan, J. Phys. C, 17, 6601, 1984.

[7] Somasundaram, T., Ganguly, P. and Rao, C.N.R., J. Phys., C, 19, pp. 213-215,1986.

[8] Yang Sup Song, Ho Keun Lee \& Nak Sam Chung, “J. Appl. Phys., 65, pp. 2568,1989.

[9] Yang Sup Song, and Nak Sam Chung, J. Appl. Phys., 67, pp.935, 1990.

[10] Orzi, D.J., Bilmes, G.M., Tocho, J.O., Mingolo, N. and Martinez, O.E., Appl. Phys. B., 66, pp. 245-249,1998.

[11] Theon, J., Marynissen,H and Dael,W.V, Phys. Rev. 26, pp. 2886, 1982.

[12] Nibu A. George, C.P.G. VAllabhan, V.P.N. Nampoori, A.K Geroge and P. Radhakrishnan., Vol. 17. pp. 315-324

[13] Bell A. G., American Journal of Science 20:305. (1880)

[14] Bell A.G., Phil Mag J Sci 11:510. 1881

[15] Rosencwaig A, Gersho., J. Apply Phys. 47:64. 197

[16] www.ksa.com/ks_electret_microphone.html 
[17] Sapna, P. Bhaskar, Parvathi C. S., and Immanuel, International Journal of Advanced Research in Electrical, Electronics and Instrumentation Engineering, Vol. 3, Issue 11, November 2014, pp. $13161-13167$.

[18] C8051F060 Microcontroller - User Manual.

[19] Sapna, and P. Bhaskar, International Journal of Scientific progress and Research (IJSPR), Vol.30, Issue 03, December 2017, pp.1-6.

[20] Hemlata B. Nirmal and Syed A. Naveed, Microcontroller Based Automatic Solar Power Tracking System, International Journal of Electrical Engineering and Technology (IJEET), Volume 4, Issue 1, January- February (2013)

[21] Jadhav Sumedh Damodhar and Phatale Aruna Prashant, Microcontroller Based Photovoltaic Battery Charging System with Buck Converter, International Journal of Electrical Engineering and Technology (IJEET), Volume 3, Issue 1, January-June (2012)

[22] Ruchika Thukral, Gulshan Kumar, Ankit Gupta, Nilesh kumar Verma, Shivanchal Asthana, Microcontroller Based Solar Power Inverter. International Journal of Electrical Engineering \& Technology, 7(5), 2016, pp. 70-78

[23] L. Shrimanth Sudheer, Immanuel J., P. Bhaskar and Parvathi C. S., Arm7 Microcontroller Based Fuzzy Logic Controller for Liquid Level Control System, International Journal of Electronics and Communication Engineering \& Technology (IJECET), Volume 4, Issue 2, March - April (2013)

[24] Mahesh Sharma and K. Singh, Automated Testing of Ni-Cd Batteries Using Microcontroller Based Charge-Discharge System, International Journal of Electrical Engineering and Technology (IJEET), Volume 5, Issue 5, May (2014), pp. 28-35

[25] Mahesh Sanjeeva, Design and Development of 4 Cylinder Gasoline Engine Model for the Verification of Complex Device Drivers Based on Infineon Tc277 Microcontroller, International Journal of Electronics and Communication Engineering \& Technology (IJECET), Volume 5, Issue 8, August (2014), pp. 71-76

\section{BIOGRAPHY}

Sapna completed her M.Sc. and M.Phil in Instrumentation Technology, from Gulbarga University Kalaburagi. Presently, she is pursuing Ph.D. under the guidance of Dr. P. Bhaskar, Professor, Department of Instrumentation Technology, Gulbarga University Post Graduate Centre, Raichur. She has published 5 papers in journals of national/international repute and presented 4 papers in national/ international conferences. Her research interests include Electrical \& Electronic Instrumentation, Scientific Instrumentation, Biomedical Instrumentation and Embedded Systems.

Immanuel J. completed his M.Sc. and M.Phil. and Ph.D. degrees in Instrumentation Technology, from Gulbarga University, Kalaburagi. Presently working as a Guest lecturer in the Department of Instrumentation Technology at Gulbarga University Post Graduate Centre, Raichur, KA, India. He has published 17 papers in journals of national/international repute and presented 7 papers in national/ international conferences. His research interests include Fuzzy Logic Controller, DSP Based Systems, MATLAB-GUI based systems, Scientific Instrumentation, Embedded Systems, VLSI and Intelligent Control Systems. He is life member of Instrument Society of India, IISc, Bangalore.

P. Bhaskar received the M.Sc., M.Phil., and Ph.D. degrees in Instrumentation from Sri Krishnadevaraya University, Anantapur, AP, India, Currently, he is a Professor in the Department of Instrumentation Technology at Gulbarga University Post Graduate Centre, Raichur, KA, India. He has published more than 60 papers in journals of national/international repute and presented over 22 papers in national/ international conferences. He has published a book on 8051 microcontrollers. His research interests include Process/Scientific/Electronic Instrumentation, Embedded Systems, and Intelligent Control Systems. He is a member of the Instrument Society of India. 